\title{
AVALIAÇÃO DE EFEITOS FÍSICO-QUÍMICOS NA EFICIÊNCIA DA BIOENCAPSULAÇÃO DE FLAVONOIDE LIPOSSOLÚVEL EM CÉLULASS DE LEVEDURA (Saccharomyces cerevisiae) ATRAVÉS DE CHOQUE OSMÓTICO
}

A. de A. CÂMARA Jr ${ }^{1}$, A. E. de M. SILVA ${ }^{1}$, R. T. P. CORREIA ${ }^{1}$ e M. R. da S. PEDRINI ${ }^{1}$.

${ }^{1}$ Universidade Federal do Rio Grande do Norte, Departamento de Engenharia Química E-mail para contato: anchietajr@gmail.com

\begin{abstract}
RESUMO - As características estruturais da levedura S. cerevisiae tornam este microrganismo um promissor veículo para a bioencapsulação de substâncias de interesse alimentício e/ou farmacológico. Dessa forma, o objetivo desse trabalho foi avaliar o efeito da concentração de fisetina (C), temperatura (T) e pressão osmótica $(\mathrm{P})$ sobre a eficiência da bioencapsulação da fisetina mediante choque osmótico. A metodologia usada para avaliar a eficiência da encapsulação (EE\%) foi a quantificação do flavonoide utilizando cromatografia líquida de alta eficiência (HPLC). O teor de fisetina internalizada (FI) foi relacionado com a EE\% e a massa de fisetina inicialmente adicionada. Os resultados mostraram que a melhor EE\% foi de $14 \%$ com $\mathrm{C}=2 \mathrm{mg} \cdot \mathrm{mL}^{-1}, \mathrm{~T}=16,6^{\circ} \mathrm{C}$ e $\mathrm{P}=30 \mathrm{MPa}$. A maior EE\% obtida através do modelo estatístico foi de $11 \%\left(\mathrm{R}^{2}=0,808\right)$ nas mesmas condições. Os melhores resultados para a FI foram de $0,494 \mathrm{mg}$ e de $0,410 \mathrm{mg}$ predito pelo modelo estatístico $\left(\mathrm{R}^{2}=0,871\right)$. Os resultados demonstram que o choque osmótico aumenta a internalização de flavonoides lipossolúveis, antes inviabilizada pela morfologia natural da célula de levedura estudada.
\end{abstract}

\section{INTRODUÇÃO}

O interesse das indústrias alimentícias por produtos que possuam em sua formulação compostos promotores da saúde humana é crescente. A fisetina (286 Da) é um flavonoide extraído de frutas como o morango, tomate, uva e pêssego, previamente apontado por sua capacidade de reduzir o avanço de células cancerígenas na próstata (Khan et al., 2008), auxiliar no tratamento de doenças neurodegenerativas (Maher, 2008) e reduzir o efeito de respostas inflamatórias pulmonares (Geraets et al., 2009). No entanto, devido a sua sensibilidade às alterações físico-químicas possui baixa biodisponibilidade in vivo (Sengupta et al., 2005). Neste caso é essencial envolver a molécula por uma membrana que seja capaz de impedir a sua degradação.

Dardelle et al. (2007) perceberam que óleos essenciais inseridos no envelope microbiano (parede e membrana celular) da levedura $S$. cerevisiae ficam protegidos mesmo com variações de temperatura, umidade e $\mathrm{pH}$. A membrana plasmática da levedura age como barreira seletora de moléculas essenciais para o seu metabolismo. Apesar disso, moléculas com pesos 
moleculares maiores que 110 Da são incapazes de passar livremente pela membrana (Dupont, 2012).

Dessa forma, estratégias para promover a internalização de componentes na célula devem ser investigadas. O choque osmótico pode ser definido como a desidratação de células microbianas com solução depressora concentrada seguido de rápida reidratação com solução isotônica. $\mathrm{O}$ choque osmótico com soluções levemente concentradas de glicerol provoca a formação de poros transientes na membrana celular da levedura S. cerevisiae (Dupont et al., 2010; Da Silva Pedrini et al., 2014). Na etapa de reidratação ocorre a entrada de água dentro da célula e consequentemente a internalização do composto suspendido/solubilizado. $O$ fácil manuseio e produção das leveduras demonstram seu forte potencial para o desenvolvimento de novos processos de bioencapsulação de flavonoides, corantes e aromas (Pham-Hoang et al., 2013).

O objetivo deste estudo foi avaliar a quantidade de fisetina bioencapsulada nas células da levedura S. cerevisiae e a eficiência do processo mediante uso de cromatografia líquida de alta eficiência (HPLC). Para isto, foram estudadas as variáveis concentração final de fisetina, pressão osmótica de desidratação e temperatura sobre o processo de bioencapsulação.

\section{MATERIAL E MÉTODOS}

\subsection{Materiais e soluções}

A fisetina, extrato de levedura e tampão fosfato-salino (PBS) foram adquiridos da SigmaAldrich (EUA). O álcool etílico absoluto, álcool metílico absoluto, ácido acético glacial, glicerol e glicose foram adquiridos da Vetec (Brasil). A peptona pancreática foi adquirida da Himedia (Îndia) e o fosfato de sódio monobásico anidro da Cromato (Brasil).

As soluções de fisetina em álcool etílico absoluto foram preparadas individualmente de acordo com a concentração final utilizada em cada ensaio. As soluções de glicerol com pressão osmótica $(\pi)$ de 1.4, 4.8, 15, 30, 45 ou 55.2 MPa foram preparadas adicionando-se $51,179,513$, $1.063,1.668$ ou $2.045 \mathrm{~g}$ de glicerol a $1000 \mathrm{~g}$ de água destilada. A atividade de água foi estimada através da Equação de Norrish (Norrish, 1966). A pressão osmótica está relacionada com a atividade de água $\left(a_{w}\right)$ de acordo com a Equação 1:

$$
\pi=\frac{-R T \ln a_{w}}{V_{w}}
$$

Onde R é a constante universal dos gases $\left(\mathrm{J}^{\mathrm{m}} \mathrm{mol}^{-1} \cdot \mathrm{K}^{-1}\right)$, T a temperatura $(\mathrm{K})$ e $\mathrm{V}_{\mathrm{w}}$ o volume parcial molar de água $\left(\mathrm{m}^{3} \cdot \mathrm{mol}^{-1}\right)$. As $a_{w}$ das soluções foram confirmadas por meio de medidor de atividade de água (Decagon devices, series 3 TE, EUA).

\subsection{Células e condições de cultivo}

Três colônias previamente isoladas da levedura S. cerevisiae (Fleischmann, Brasil) foram adicionadas a $100 \mathrm{~mL}$ do meio Malt Wickerham modificado (Dupont et al., 2010), para $1 \mathrm{~L}$ : $3 \mathrm{~g}$ de extrato de levedura, $3 \mathrm{~g}$ de peptona pancreática, $10 \mathrm{~g}$ de glicose, $51 \mathrm{~g}$ de glicerol e $1,5 \mathrm{~g}$ fosfato de sódio monobásico anidro, em seguida incubadas sob agitação (Tecnal, Brasil, 
modelo TE422) a $250 \mathrm{rpm}, 48 \mathrm{~h}$ e $25^{\circ} \mathrm{C}$. Alíquota $(1 \mathrm{~mL})$ da suspensão foi transferida para $100 \mathrm{~mL}$ do mesmo meio e mantido nas mesmas condições por mais $24 \mathrm{~h}$. Centrifugou-se $40 \mathrm{~mL}$ desta suspensão por $5 \mathrm{~min}$ e $2200 \times \mathrm{g}$ (Solab, Brasil, modelo SL701). O precipitado foi lavado 2 vezes com a solução isotônica de glicerol $(1.4 \mathrm{MPa})$ e ressuspendido em $20 \mathrm{~mL}$ da mesma solução.

\subsection{Choque osmótico e bioencapsulação da fisetina}

Transferiu-se 1,5 mL da suspensão para microtubo e centrifugou-se a $5100 \times \mathrm{g}$ durante 10 min. Ao precipitado foi adicionado o mesmo volume de glicerol a 4.8, 15, 30, 45 ou 55.2 MPa. As células foram incubadas em agitação por $1 \mathrm{~h}$ com temperatura de 16.6, 20, 25, 30 ou $33.4{ }^{\circ} \mathrm{C}$. As células foram centrifugadas e reidratadas com a solução isotônica. Imediatamente adicionou-se $300 \mu \mathrm{L}$ de fisetina com concentração final de $0.32,1,2,3$, ou $3.68 \mathrm{mg} \cdot \mathrm{mL}^{-1}$. As células foram lavadas 3 vezes com álcool etílico, ressuspendidas em PBS e liofilizadas.

\subsection{Extração e quantificação}

Foram pesados $20 \mathrm{mg}$ da levedura liofilizada, adicionados $5 \mathrm{~mL}$ de álcool etílico $50 \%$ (v/v) e incubado sob agitação por $60 \mathrm{~min}$. As amostras foram filtradas em membrana de nylon (poro de $0,45 \mu \mathrm{m}$ ) e a leitura realizada em HPLC (Shimadzu, modelo LC-10ATvp, Japão) acoplado a uma coluna C18 $(150 \mathrm{~mm} \times 3,9 \mathrm{~mm}, 5 \mu \mathrm{m})$ em condições isocráticas. A fase móvel constituída de água destilada:álcool metílico:ácido acético glacial (440:550:10 v/v/v). Vazão $1,0 \mathrm{~mL} \cdot \mathrm{min}^{-1}$ e volume de injeção $20 \mu \mathrm{L}$. A detecção foi realizada com detector UV-VIS a $360 \mathrm{~nm}$. A área do pico de emissão de cada amostra foi relacionada com a curva padrão da fisetina. A eficiência da encapsulação (\%EE) foi calculada conforme a Equação 2:

$$
E E \%=\frac{C_{E}}{C_{i}} \times 100
$$

Onde, $\mathrm{C}_{\mathrm{E}}$ é a concentração de fisetina encapsulada e $\mathrm{C}_{\mathrm{i}}$ a concentração de fisetina adicionada inicialmente. A quantificação da massa de fisetina internalizada (FI) foi estimada através da regressão dos valores da EE\% e da quantidade de fisetina inicialmente adicionada (Volume final $=1,8 \mathrm{~mL}$ ) de acordo com a Equação 3.

$$
F I=\frac{C_{i} \times E E \% \times 1,8}{100}
$$

\subsection{Planejamento experimental}

Utilizou-se a metodologia de delineamento composto central rotacional (DCCR) $2^{3} \mathrm{com}$ 3 pontos fatoriais, 6 pontos axiais e 4 repetições no ponto central para avaliar o processo de bioencapsulação da fisetina. As variáveis estudadas foram a concentração de fisetina, a pressão osmótica de desidratação e a temperatura do sistema. A matriz completa do DCCR com as variáveis codificadas, reais e as respostas pode ser observada na Tabela 1. Cada ensaio foi realizado em triplicata para aumentar a confiabilidade dos resultados e a reprodutibilidade do processo. 
Tabela 1 - Matriz do DCCR para os três fatores e as respostas eficiência da encapsulação e fisetina internalizada

\begin{tabular}{llcccc}
\hline Ensaio & $\begin{array}{l}\mathrm{C}\left(\mathrm{mg} \cdot \mathrm{mL}^{-1}\right) \\
\left(\mathrm{X}_{1}\right)\end{array}$ & $\begin{array}{l}\mathrm{P}(\mathrm{MPa}) \\
\left(\mathrm{X}_{2}\right)\end{array}$ & $\begin{array}{l}\mathrm{T}\left({ }^{\circ} \mathrm{C}\right) \\
\left(\mathrm{X}_{3}\right)\end{array}$ & $\begin{array}{l}\mathrm{EE}(\%) \\
\left(\mathrm{Y}_{1}\right)\end{array}$ & $\begin{array}{l}\text { FI }(\mathrm{mg}) \\
\left(\mathrm{Y}_{2}\right)\end{array}$ \\
\hline 01 & $-1(1,0)$ & $-1(15,0)$ & $-1(20,0)$ & $1,26 \pm 0,19$ & 0,023 \\
02 & $-1(1,0)$ & $-1(15,0)$ & $1(30,0)$ & $1,02 \pm 0,12$ & 0,018 \\
03 & $-1(1,0)$ & $1(45,0)$ & $-1(20,0)$ & $1,33 \pm 0,13$ & 0,024 \\
04 & $-1(1,0)$ & $1(45,0)$ & $1(30,0)$ & $1,72 \pm 0,22$ & 0,031 \\
05 & $1(3,0)$ & $-1(15,0)$ & $-1(20,0)$ & $1,76 \pm 0,68$ & 0,095 \\
06 & $1(3,0)$ & $-1(15,0)$ & $1(30,0)$ & $1,73 \pm 0,32$ & 0,093 \\
07 & $1(3,0)$ & $1(45,0)$ & $-1(20,0)$ & $3,12 \pm 2,95$ & 0,168 \\
08 & $1(3,0)$ & $1(45,0)$ & $1(30,0)$ & $2,74 \pm 1,99$ & 0,148 \\
09 & $-1,682(0,32)$ & $0(30,0)$ & $0(25,0)$ & $3,16 \pm 0,15$ & 0,018 \\
10 & $1,682(3,68)$ & $0(30,0)$ & $0(25,0)$ & $0,41 \pm 0,09$ & 0,027 \\
11 & $0(2,0)$ & $-1,682(4,8)$ & $0(25,0)$ & $0,53 \pm 0,14$ & 0,019 \\
12 & $0(2,0)$ & $1,682(55,2)$ & $0(25,0)$ & $0,62 \pm 0,05$ & 0,022 \\
13 & $0(2,0)$ & $0(30,0)$ & $-1,682(16,6)$ & $13,73 \pm 3,59$ & 0,494 \\
14 & $0(2,0)$ & $0(30,0)$ & $1,682(33,4)$ & $10,47 \pm 0,59$ & 0,377 \\
15 & $0(2,0)$ & $0(30,0)$ & $0(25,0)$ & $0,65 \pm 0,17$ & 0,023 \\
16 & $0(2,0)$ & $0(30,0)$ & $0(25,0)$ & $0,79 \pm 0,13$ & 0,028 \\
17 & $0(2,0)$ & $0(30,0)$ & $0(25,0)$ & $0,69 \pm 0,14$ & 0,025 \\
18 & $0(2,0)$ & $0(30,0)$ & $0(25,0)$ & $0,51 \pm 0,13$ & 0,018 \\
\hline $\mathrm{X}_{1}=(\mathrm{C}-2,00), \mathrm{X}_{2}=(\mathrm{P}-30,0) / 15,0 \mathrm{e} \mathrm{X} \mathrm{X}_{3}=(\mathrm{T}-25,0) / 5,0$. Valores médios \pm desvio padrão (n=3 repetições).
\end{tabular}

\subsection{Análise Estatística}

Os modelos de segunda ordem representativos do processo estudado foram obtidos através do ajuste dos valores experimentais (Tabela 1) pelo método dos mínimos quadrados. Os dois modelos propostos para as resposta $\left(\mathrm{Y}_{1}\right.$ e $\left.\mathrm{Y}_{2}\right)$ foram baseados na Equação 4:

$$
Y_{i}=\beta_{0}+\beta_{1} X_{1}+\beta_{2} X_{2}+\beta_{3} X_{3}+\beta_{11} X_{1}^{2}+\beta_{22} X_{2}^{2}+\beta_{33} X_{3}^{2}+\beta_{12} X_{1} X_{2}+\beta_{13} X_{1} X_{3}+\beta_{23} X_{2} X_{3}
$$

Onde $Y_{\mathrm{i}}$ é o termo dependente dos valores dos coeficientes. $\beta_{0}, \beta_{\mathrm{i}}, \beta_{\mathrm{ii}}$ e $\beta_{\mathrm{ij}}$ são os coeficientes da média, lineares, quadráticos e das interações entre os termos, respectivamente. A regressão dos coeficientes do modelo, as superfícies de resposta e a análise de variância (ANOVA) foram calculados e analisados por meio do software STATISTICA v7.0.

\section{RESULTADOS E DISCUSSÕES}

\subsection{Avaliação do modelo estatístico}

Neste estudo foram avaliadas a eficiência da encapsulação e a massa de fisetina internalizada nas células. Na Tabela 2 estão os coeficientes de regressão dos modelos. Os valores dos efeitos estatisticamente não significativos ( $t$ Student $)$ foram retirados do modelo de segunda ordem e a qualidade do modelo em representar as respostas $\left(\mathrm{Y}_{1} \mathrm{e} \mathrm{Y}_{2}\right)$ foram analisadas através da Análise de variância (ANOVA) e do teste F mostrado na Tabela 3. 
Tabela 2 - Coeficientes estimados para o ajuste do modelo de segunda ordem

\begin{tabular}{lll}
\hline Coeficiente & $\begin{array}{l}\text { Eficiência da } \\
\text { Encapsulação } \\
(\%)\end{array}$ & $\begin{array}{l}\text { Fisetina } \\
\text { Internalizada } \\
(\mathrm{mg})\end{array}$ \\
\hline$\beta_{0}$ & 0,817 & 0,028 \\
$\beta_{1}$ & $\mathrm{NS}$ & 0,031 \\
$\beta_{11}$ & $-0,303$ & $-0,020$ \\
$\beta_{2}$ & 0,241 & 0,011 \\
$\beta_{22}$ & -0.731 & $-0,021$ \\
$\beta_{3}$ & $-0,420$ & $-0,016$ \\
$\beta_{33}$ & 3,344 & 0,126 \\
$\beta_{12}$ & 0,200 & 0,014 \\
$\beta_{13}$ & $\mathrm{NS}$ & $\mathrm{NS}$ \\
$\beta_{23}$ & $\mathrm{NS}$ & $\mathrm{NS}$ \\
\hline $\mathrm{NS}=$ não significativo $(\mathrm{p}>0,05)$. &
\end{tabular}

Tabela 3 - Análise de variância (ANOVA) dos modelos de segunda ordem em função das respostas eficiência da encapsulação $(\mathrm{EE} \%)$ e fisetina internalizada $(\mathrm{FI})$ através do DCCR

\begin{tabular}{lllllllll}
\hline \multirow{2}{*}{$\begin{array}{l}\text { Fonte de } \\
\text { variação }\end{array}$} & \multicolumn{2}{l}{$\begin{array}{l}\text { Soma de } \\
\text { quadrados }\end{array}$} & \multicolumn{3}{l}{$\begin{array}{l}\text { Graus de } \\
\text { liberdade }\end{array}$} & Quadrado Médio & F calc & \\
\cline { 2 - 9 } & EE\% & FI & EE\% & FI & EE\% & FI & EE\% & FI \\
\hline Regressão & 179,838 & 0,2692 & 6 & 7 & 29,973 & 0,03845 & 7,70 & 9,64 \\
Resíduos & 42,800 & 0,0399 & 11 & 10 & 3,891 & 0,00399 & - & - \\
Falta de ajuste & 42,760 & 0,0399 & 8 & 7 & 5,345 & 0,00569 & 396,91 & 326,32 \\
Erro puro & 0,040 & 0,0001 & 3 & 3 & 0,013 & 0,00002 & - & - \\
Total & 222,638 & 0,3091 & 17 & 17 & - & - & - & - \\
$\mathrm{R}^{2}$ & 0,808 & 0,871 & - & - & - & - & - & - \\
\hline
\end{tabular}

EE\%: $F_{\text {tab }(6 ; 11 ; 0,05)}=3,09 ; F_{\text {tab }(8 ; 3 ; 0,05)}=8,85 ;$ p-valor $<0,0001$

FI: $\mathrm{F}_{\text {tab }(7 ; 10 ; 0,05)}=3,14 ; \mathrm{F}_{\text {tab }(7 ; 3 ; 0,05)}=19,30 ; \mathrm{p}$-valor $<0,0001$

$O$ valor do $F_{\text {calc }}(7,70)$ para $E E \%$ foi cerca de 2,5 vezes superior ao valor do $F_{\text {tab }}(3,09)$ para os mesmos graus de liberdade. Para a FI o valor do $F_{\text {calc }}(9,64)$ foi 3 vezes superior ao $F_{\text {tab }}$ $(3,14)$. Isto significa que os valores experimentais estão sendo preditos de maneira eficiente pelos modelos propostos, ou seja, o nível de significância dos modelos é superior a $95 \%$. Os coeficientes de determinação $\left(\mathrm{R}^{2}\right)$ mostram que cerca de $80,8 \%$ e $87,1 \%$ das respostas podem ser explicadas pelos modelos para EE\% e FI, respectivamente. Os valores elevados de $\mathrm{F}_{\text {calc }}$ na falta de ajuste demonstram que as variáveis que foram excluídas do modelo não estão sendo bem representadas. Contudo, os modelos estão muito bem ajustados na região de interesse, ou seja, na área onde encontram-se os valores de maior EE\% e FI.

\subsection{Superfícies de resposta}

As superfícies de resposta dos modelos da eficiência da encapsulação e da massa de fisetina internalizada nas células de levedura estão mostradas na Figura 1. A comparação gráfica das superfícies foi adotada como método de avaliação da melhor resposta obtida pelo modelo estatístico e a definição das condições otimizadas do processo. 


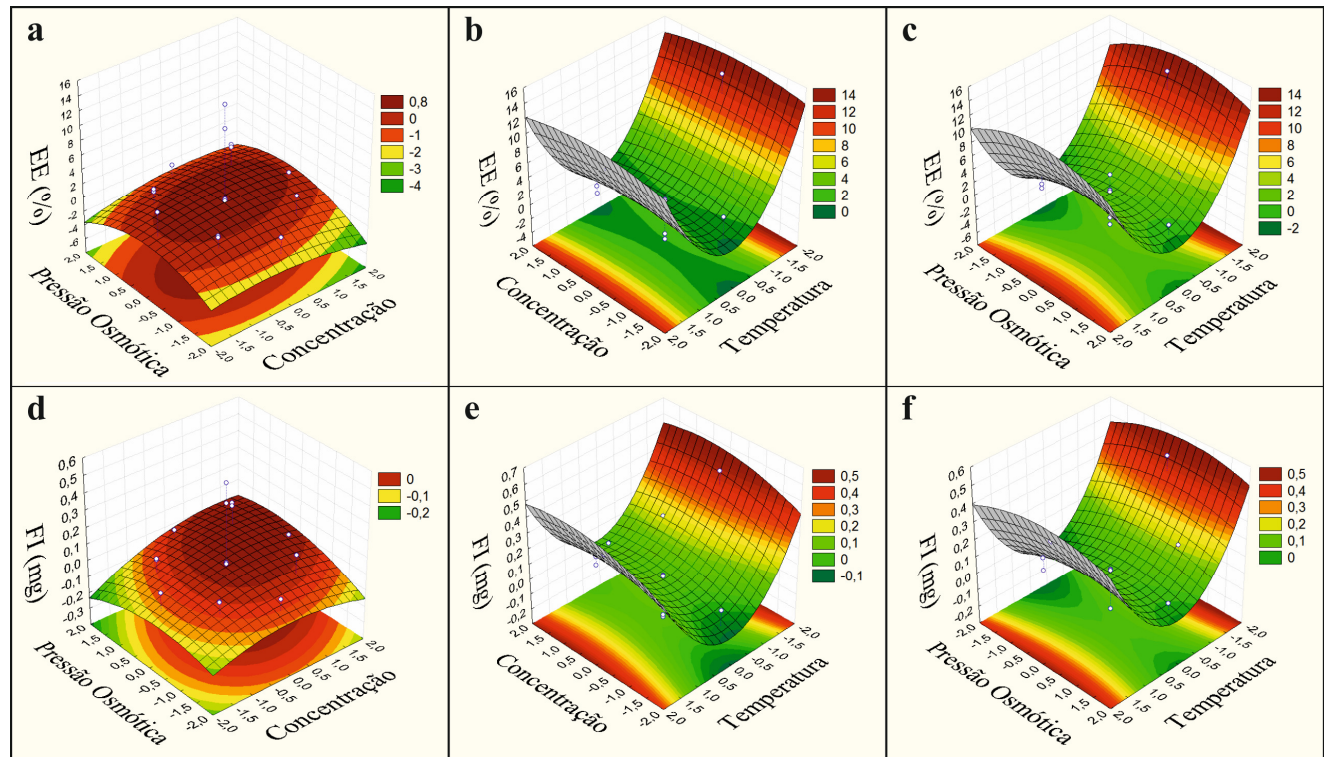

Figura 1 - Superfícies de resposta da eficiência da encapsulação (a-c) e fisetina internalizada (d-f) em função da Pressão Osmótica $\times$ Concentração, Concentração $\times$ Temperatura e Pressão Osmótica $\times$ Temperatura.

\subsection{Efeito da concentração de fisetina}

O efeito linear da concentração da fisetina não foi significativo para a EE\%. Já o efeito quadrático foi significativo e negativo, e o efeito da interação entre a concentração e a pressão osmótica foi positivo e significativo (Tabela 3). Os melhores valores encontram-se na região central do gráfico com $\mathrm{C}=2 \mathrm{mg} \cdot \mathrm{mL}^{-1}$ (Figura 1a-b). De maneira análoga, foi observado na quantificação de FI, diferenciando-se somente pelo termo linear $\left(\beta_{1}\right)$ que foi significativo e positivo. Observou-se o aumento da quantidade FI ligeiramente proporcional à sua concentração (Figura 1d-e), portanto os melhores valores da FI foram observados na região central-superior do gráfico com $\mathrm{C} \geq 2 \mathrm{mg} \cdot \mathrm{mL}^{-1}$. É evidente que a $\mathrm{EE} \%$ não obrigatoriamente deve corresponder a maior quantidade de FI, uma vez que a FI é dependente da quantidade de fisetina inicialmente adicionada, enquanto que a $\mathrm{EE} \%$ é calculado como a relação entre a concentração de fisetina encapsulada e a concentração inicialmente adicionada (Equação 2 e 3 ).

\subsection{Efeito da pressão osmótica de desidratação}

O efeito linear da pressão osmótica sobre a EE\% foi positivo e relativamente baixo em comparação ao valor da média e negativo para o termo quadrático (Tabela 3). Os melhores valores da $E E \%$ ficaram na região central com $\mathrm{P}=30 \mathrm{MPa}$ (Figura 1a/c). Em relação a FI os melhores resultados foram encontrados na região central-superior das superfícies (Figura 1d/f) entre 30 e 55,2 MPa. Dupont et al. (2010) perceberam que o aumento excessivo da pressão osmótica do meio leva a desestabilização irreversível da membrana plasmática, o que pode representar o extravasamento do conteúdo intracelular e a redução da EE\%. Em contrapartida pressões osmóticas reduzidas não afetam a estrutura da célula e a substância é impedida de atravessar a membrana celular devido a sua morfologia natural. Neste caso não se observa o efeito da osmoporação celular (Câmara Júnior et al., 2013; Pedrini et al., 2014). Sendo assim, considera-se o valor otimizado na região de central a $30 \mathrm{MPa}$. 


\subsection{Efeito da temperatura do sistema}

Em ambos os casos, o termo linear foi negativo e o termo quadrático positivo, por essa razão constatou-se um comportamento positivo nos extremos do gráfico das superfícies, em $\mathrm{T} \leq 16,6{ }^{\circ} \mathrm{C}$ e $\mathrm{T} \geq 33,4{ }^{\circ} \mathrm{C}$ (Figura 1b-c e 1e-f). Provavelmente a fisetina foi conservada em temperaturas mais baixas, levando a um aumento na intensidade do pico de emissão no HPLC. Já as temperaturas mais elevadas podem ter causado maior choque osmótico e aumento do número e/ou tamanho dos poros formados na membrana celular da levedura, levando a maior entrada de água e fisetina na célula e consequentemente maior EE\%. A possível degradação causada pela temperatura mais elevada pode ter sido evitada devido a estrutura protetora da célula de levedura, que tem se demonstrado capaz de suportar altas temperaturas e manter a integridade dos componentes nela inseridos (Normand et al., 2005). Considerou-se a temperatura de $16,6^{\circ} \mathrm{C}$ como ideal por ter sido encontrado maior números de pontos ótimos nesta temperatura (Figura 1).

\subsection{A osmoporação influencia a EE\% e FI}

Neste estudo foi constatado que a osmoporação promoveu aumento na EE\% e na FI. Os melhores resultados experimentais foram de $14 \%$ para a EE\% e de 0,494 mg para a FI. Os valores preditos pelos modelos foram de $11 \%$ para EE\% e de $0,410 \mathrm{mg}$ para a FI. Paramera et al. (2011) utilizaram células da levedura $S$. cerevisiae plasmolisadas com cloreto de sódio para encapsular o corante lipossolúvel curcumina. Os autores reportaram valores próximos com uma EE\% em média de $20 \%$. Os resultados mostrados aqui levam a crer que as lavagens das células com o álcool etílico absoluto podem ter arrastado parte do componente internalizado e reduzido a EE\% (Pham-Hoang et al., 2013).

A principal barreira do processo de bioencapsulação é a membrana plasmática que impede a entrada passiva de substâncias no citoplasma da célula (Pedrini et al., 2014). Dupont et al. (2010) constataram a existência de um mecanismo de formação de poros na membrana celular da levedura $S$. cerevisiae em função da pressão osmótica do meio. Resultados qualitativos publicados anteriormente mostraram que células da levedura $S$. cerevisiae foram capazes de encapsular instantaneamente grandes quantidades de fisetina quando submetidas ao choque osmótico a 30 MPa (Câmara Júnior et al., 2013). Da mesma forma, Pedrini et al. (2014) encontraram resultados qualitativos semelhantes para molécula hidrossolúvel FITC-Dextran (20 kDa) quando não aplicada a osmoporação.

\section{CONCLUSÕES}

O choque osmótico mostra-se como uma estratégia tecnológica promissora para aumentar a eficiência da bioencapsulação de componentes lipossolúveis em células da levedura $S$. cerevisiae. Neste estudo as melhores condições foram encontradas com $\mathrm{C}=2 \mathrm{mg} \cdot \mathrm{mL}^{-1}$, $\mathrm{P}=30 \mathrm{MPa}$ e $\mathrm{T}=16,6{ }^{\circ} \mathrm{C}$. Os modelos estatísticos de segunda ordem obtidos foram estatisticamente significativos, com $\mathrm{R}^{2}=0,808$ para a $E E \%$ e $\mathrm{R}^{2}=0,871$ para a FI. A eficiência do processo de bioencapsulação de compostos lipofílicos por choque osmótico poderia ser aprimorada com a utilização de métodos de quantificação que não utilizem solventes orgânicos na etapa de extração. Estes solventes podem desidratar, danificar o envelope celular, solubilizar os componentes intracelulares e reduzir a EE\%. 


\section{REFERÊNCIAS}

CÂMARA JÚNIOR, A. A.; PEDRINI, M. R. S.; CORREIA, R. T. P. Mecanismo de incorporação de antioxidante fluorescente fisetina em células de levedura. In: SIMPÓSIO NACIONAL DE BIOPROCESSOS, Foz do Iguaçu. ABEQ, p. 164, 2013.

DARDELLE, G.; NORMAND, V.; STEENHOUDT, M.; BOUQUERAND, P.-E.; CHEVALIER, M.; BAUMGARTNER, P. Flavour-encapsulation and flavour-release performances of a commercial yeast-based delivery system. Food Hydrocolloids, v. 21, n. 5-6, p. 953-960, 2007.

DUPONT, S. Implication de la membrane plasmique dans la survie de Saccharomyces cerevisiae lors de perturbations hydriques: role cle de l'ergosterol. 176f. Thèse (Docteur en Sciences des Aliments). AgroSup Dijon, Université de Bourgogne, França, 2012.

DUPONT, S.; BENEY, L.; RITT, J.-F.; LHERMINIER, J.; GERVAIS, P. Lateral reorganization of plasma membrane is involved in the yeast resistance to severe dehydration. Biochim. Biophys. Acta-Biomembr., v. 1798, n. 5, p. 975-985, 2010.

GERAETS, L.; HAEGENS, A.; BRAUERS, K.; HAYDOCK, J. A.; VERNOOY, J. H.; WOUTERS, E. F.; BAST, A.; HAGEMAN, G. J. Inhibition of LPS-induced pulmonary inflammation by specific flavonoids. Biochem. Biophys. Res. Commun., v. 382, n. 3, p. 598-603, 2009.

KHAN, N.; ASIM, M.; AFAQ, F.; ABU ZAID, M.; MUKHTAR, H. A novel dietary flavonoid fisetin inhibits androgen receptor signaling and tumor growth in athymic nude mice. Cancer Res., v. 68, n. 20, p. 8555-63, 2008.

MAHER, P. The flavonoid fisetin promotes nerve cell survival from trophic factor withdrawal by enhancement of proteasome activity. Arch. Biochem. Biophys., v. 476, n. 2, p. 139-44, 2008 .

NORMAND, V.; DARDELLE, G.; BOUQUERAND, P.-E.; NICOLAS, L.; JOHNSTON, D. J. Flavor Encapsulation in Yeasts: Limonene Used as a Model System for Characterization of the Release Mechanism. J. Agric. Food Chem., v. 53, n. 19, p. $7532-$ 7543, 2005.

NORRISH, R. S. An equation for the activity coefficients and equilibrium relative humidities of water in confectionery syrups. Int. J. Food Sci. Technol., v. 1, n. 1, p. 25-39, 1966.

PARAMERA, E. I.; KONTELES, S. J.; KARATHANOS, V. T. Microencapsulation of curcumin in cells of Saccharomyces cerevisiae. Food Chem., v. 125, p. 892-902, 2011.

PEDRINI, M. R. S.; DUPONT, S.; CÂMARA JÚNIOR, A. A.; BENEY, L.; GERVAIS, P. Osmoporation: a simple way to internalize hydrophilic molecules into yeast. Appl. Microbiol. Biotechnol., v. 98, n. 3, p. 1271-1280, 2014.

PHAM-HOANG, B. N.; ROMERO-GUIDO, C.; PHAN-THI, H.; WACHE, Y. Encapsulation in a natural, preformed, multi-component and complex capsule: yeast cells. Appl. Microbiol. Biotechnol., v. 97, n. 15, p. 6635-45, 2013.

SENGUPTA, B.; BANERJEE, A.; SENGUPTA, P. K. Interactions of the plant flavonoid fisetin with macromolecular targets: insights from fluorescence spectroscopic studies. $J$. Photochem. Photobiol. B-Biol., v. 80, n. 2, p. 79-86, 2005. 